\title{
Models of Gender Differences in Cardiovascular Disease
}

\author{
Richard D. Patten, M.D. \\ Molecular Cardiology Research Institute, Tufts-New England Medical Center, 750 Washington \\ Street, Boston, MA 02111, Phone: 617-636-0615, Fax:617-636-5649, Email: rpatten@tufts- \\ nemc.org
}

\section{Abstract}

Clinical observations made over several decades support the existence of gender differences in cardiovascular disease prevalence and severity. For example, women exhibit a delay in the onset of vascular disease compared to men and the temporal link between menopause and the rise in vascular events in women suggests that ovarian hormones may be important in reducing the risk of vascular disease in women. Gender differences have also been observed in the severity and outcome of myocardial diseases such that women with heart failure have a better prognosis than men coupled with gender-specific patterns of ventricular remodeling. These clinical observations have fostered great interest in understanding the mechanisms of gender differences in cardiovascular diseases with the goal being to identify novel therapeutic targets. The purpose of this review is to describe animal models of cardiovascular disease that have demonstrated clear gender differences in the pathophysiologic responses to a given stimulus. Animal models from two broad areas of cardiovascular investigation will be highlighted: vascular disease and heart failure.

\section{Introduction}

Clinical observations made over several decades support the existence of gender differences in cardiovascular disease prevalence and severity. Indeed, women have long been known to exhibit a delay in the development of vascular disease manifest by myocardial infarction (MI) and peripheral vascular disease compared to men suggesting that female gender offers protection from the development of atherosclerosis.[1] The temporal link between menopause and the rise in vascular events in women suggests that ovarian hormones may be important in reducing the risk of vascular disease in women.[2]

Gender differences have also been observed in the severity and outcome of myocardial diseases. For example, women with heart failure have a better prognosis than men irrespective of heart failure etiology or ejection fraction.[3] Improved heart failure prognosis among women is coupled with a gender-specific remodeling phenotype.[4] In pressure overload states such as hypertension or aortic stenosis, women's hearts typically develop a pattern of concentric remodeling characterized by an increase in left ventricular (LV) wall thickness with maintenance of chamber size while men's hearts develop eccentric hypertrophy characterized by a LV dilatation without an increase in wall thickness. [5-8] These clinical observations have fostered great interest in understanding the mechanisms of these gender differences in cardiovascular diseases with the goal being to identify novel therapeutic targets. The purpose of this review is to describe animal models of cardiovascular disease that have demonstrated

\footnotetext{
Publisher's Disclaimer: This is a PDF file of an unedited manuscript that has been accepted for publication. As a service to our customers we are providing this early version of the manuscript. The manuscript will undergo copyediting, typesetting, and review of the resulting proof before it is published in its final citable form. Please note that during the production process errors may be discovered which could affect the content, and all legal disclaimers that apply to the journal pertain.
} 
clear gender differences in the pathophysiologic responses to a given stimulus. Animal models from two broad areas of cardiovascular investigation will be highlighted: vascular disease and heart failure.

\section{Gender and Models of Vascular Disease}

Vascular disease models can be subdivided into those that induce atherosclerosis or vascular injury (See Table 1). Models of atherosclerosis utilize susceptible species fed a high cholesterol diet. Vascular injury studies are characterized by a given stimulus that damages the endothelial layer within a target vessel leading to intimal hyperplasia and an increase in medial thickness.

\section{Models of Atherosclerosis}

The notion that female gender confers protection from atherosclerosis and its consequences have been recognized for at least 50 years.[9] More recently, Hamm observed in a primate model (cynomolgus macaques) that a diet high in cholesterol $(0.56 \mathrm{mg} / \mathrm{cal})$ led to the development of significant coronary artery atherosclerosis in monkeys compared to controls fed normal chow.[10] In this model, female macaques developed significantly less coronary artery atherosclerosis than males.[10] This same group reported that the development of atherosclerosis in females was accelerated if they underwent ovariectomy before administration of the high cholesterol diet.[11] These data therefore support that ovarian hormones may, in part, mediate female gender-associated protection from the development of atherosclerosis.

Similarly, New Zealand White Rabbits develop aortic atherosclerosis when fed a high cholesterol diet ( $2 \%$ of total caloric intake). Hayashi et al observed that following 10 weeks of a high cholesterol diet, female rabbits developed only mild atherosclerosis occupying $10 \%$ of the total luminal surface of the aorta compared to males that exhibited atherosclerosis that covered $42 \%$ of the luminal surface are of the aorta.[12] Further experiments showed that higher nitric oxide release from the aortic endothelium of females likely contributed to protection from atherosclerosis. Hayashi showed further in ovariectomized female rabbits that supplemental oral estrogen replacement inhibited atherosclerotic plaque area compared to ovariectomized rabbits not treated with estrogen [13] implicating a protective effect of estrogen in this model.

\section{Models of Vascular Injury}

These models differ primarily in the method used to injure a target vessel. Many investigators have utilized intraluminal injury such as a wire (mouse) or balloon (rat and rabbit) to disrupt and denude the endothelial layers of the vascular wall. Other models induce an extra-luminal inflammatory response within the adventitia (e.g. cuff placement around a vessel) or arterial ligation that leads to neointimal hyperplasia and increased medial area secondary to smooth muscle cell proliferation. This peri-arterial cuff placement model was utilized by Moroi et al who characterized the injury response in femoral arteries of wild type mice.[14] Intimal and medial areas quantified by histologic techniques were lower in females compared to males whereas female mice deficient in endothelial nitric oxide synthase (eNOS) demonstrated comparable increases in intimal and medial thickness as males [14] supporting a role for eNOS and nitric oxide in the vascular protection associated with female gender. Tolbert et al applied the carotid arterial ligation model to wild type male and female mice and demonstrated significantly less increase in intimal hyperplasia and medial thickness in females compared to males (Figure 1).[15] Protection from intimal and medial hyperplasia was lost upon ovariectomy and restored by estrogen replacement supporting a role for estrogens in the vascular protection associated with female gender in this model. Akishita reported similar findings in a rat model in which a 3 fold increase in the intima/media thickness ratio was 
observed in males compared to females 14 days following cuff-induced injury to the femoral artery.[16] This group also observed significantly less vascular smooth muscle cell proliferation in females compared to males.[16]

In rats, neointimal proliferation and an increase in medial thickness of the carotid artery can be induced by balloon injury by insertion of a 2 French Fogarty into the common carotid where the balloon is inflated and pulled back to the external carotid several times to denude the endothelium layer. Using this model, Chen et al showed that the increase in intimal and medial area14 days following balloon injury was greater in male rats compared to females.[17]

\section{Models of Aortic Aneurysm Formation}

Recently, models of abdominal aortic aneurysm (AAA) formation have been developed. Ailawadi et al utilized rats in which the infrarenal portion of the aorta was surgically isolated and perfused for 60 minutes with porcine pancreatic elastase diluted in saline. Aortas were then evaluated 7 or 14 days later with aneurysm formation defined as a $100 \%$ increase in aortic diameter over the pre-defined time period.[18] In this clinically relevant model, Ailawadi et al observed a higher frequency and severity of aortic aneurysms in males that was associated with greater inflammatory cell infiltrates and matrix metalloproteinase (MMP) 9 activities compared to females. Administration of supplemental estradiol to males limited aneurysm size, inflammatory infiltrates, and MMP9 activity supporting that these gender differences are, in part, secondary to protective effects of estradiol. In a subsequent study, this same group demonstrated lower leukocyte recruitment and cytokine gene expression in female aortas compared to male.[19]

The disease models summarized above represent a small cross section of examples in which female gender reproducibly is associated with protection from the development of atherosclerosis or vascular injury. Although data are limited, much of this effect appears to be mediated by ovarian hormones with most evidence pointing specifically to a favorable influence of estrogens that are likely mediated through estrogen receptor (ER) [20] mediated activation of nitric oxide synthase production making ERs plausible targets for drug discovery in the treatment of vascular disease. Importantly, these models largely recapitulate what is known in the human epidemiology literature demonstrating reduced incidence and protection from vascular events in premenopausal females.[2] Furthermore, these gender differences noted in these models underscore that care must be taken when planning and conducting experiments utilizing these or similar models such that the disease phenotype in females may very well be less pronounced than that observed in males.

\section{Gender Differences in Models of Heart Failure and LV Remodeling}

LV remodeling is a term that refers to alterations in LV mass, chamber size and shape in response to a given stimulus such as myocardial injury, pressure or volume overload. Within many such heart failure models, female gender has been shown by many to influence mortality, heart failure severity, and the patterns of LV remodeling (See Table 2). The broad theme from these studies is that female gender confers protection from apoptosis and hypertrophy both of which contribute to progressive LV dilation and dysfunction. Heart failure models can be categorized broadly into myocardial injury (e.g. ischemia-reperfusion injury and permanent coronary ligation), pressure overload (hypertension, aortic constriction), or volume overload (AV Fistula, aortic or mitral regurgitation). Additionally, multiple transgenic or knockout mouse models of hypertrophic or dilated cardiomyopathy have been described in which female gender delays the onset of heart failure and improves mortality compared to males. 


\section{Myocardial Injury Models}

Gender differences have been well established in models of ischemia reperfusion injury (recently reviewed in [21]). For example, in an in vitro, global ischemia-reperfusion model using Langendorff-perfused rat hearts, Bae and Zhang observed significantly less myocardial injury in female vs. male hearts ( $23 \%$ relative reduction) following 25 minutes of ischemia and 2 hours of reperfusion.[22] Pharmacologic inhibitor experiments further showed that reduced myocardial injury in females was dependent on the phosphatidylinositol-3 kinase and protein kinase $\mathrm{C}$ epsilon (PKC $\mathrm{P}$ ) signaling pathways. Brown et al[23] demonstrated in a similar model that protection from injury in females was dependent on functional sarcolemmal $\mathrm{K}_{\mathrm{ATP}}$ channels. Wang et al performed in vitro, global ischemia experiments in Langendorff-perfused mouse hearts subjected to 20 minutes of ischemia followed by 60 minutes of reperfusion and observed reduced myocardial injury in female compared to male hearts, an effect that was lost in estrogen receptor $\alpha$ knockout mice supporting a role for this estrogen receptor isoform. [24] Gender differences, however, are not universal to all models of ischemia-reperfusion injury as exemplified by lack of an effect of female gender in an in vivo dog model.[25]

Permanent coronary ligation models are probably most appropriate to study heart failure and $\mathrm{LV}$ remodeling following myocardial infarction. The number of papers demonstrating an effect of gender in these models is relatively scant compared to those for ischemia reperfusion injury. One study by Cavasin et al showed that compared to females, wild type male mice exhibited a higher incidence of myocardial rupture associated with greater neutrophil cell infiltration and increased matrix metalloproteinase activity within the first few days following coronary ligation. In the chronic phase, males developed greater hypertrophy, LV dilatation and LV dysfunction compared to females.[26] We showed in wild type, ovariectomized female mice that physiologic estrogen replacement modestly reduced infarct size but led to a doubling of mortality coupled with greater LV hypertrophy and dilation compared to ovariectomized females treated with placebo.[27] Thus, if female gender is indeed protective following permanent coronary ligation, our data supports that this effect is not mediated by estrogens.

\section{Pressure Overload Models}

Models of pressure overload have perhaps yielded the most consistent reports of gender differences in the patterns of LV remodeling and hypertrophy. In numerous models female gender confers protection from the development of overt heart failure, LV dilatation and systolic dysfunction (See Figure 2). Tamura et al[28] showed in spontaneously hypertensive heart failure rats that compared to males, females exhibited preserved LV function and a delay in the onset of heart failure (24 vs. 18 months). In the rat ascending aortic constriction model of pressure overload Douglas et al [29] reported that female gender was associated with protection from chamber dilatation and an increase in wall thickness consistent with a more compensated pattern of hypertrophy. Female hearts had better contractile reserve compared to males as indicated by measures of peak LV pressure and dP/dt. Similarly, Weinberg et al assessed contractility by ex vivo pressure-volume analyses and showed that in response to pressure overload in rats, hearts from females' demonstrated normal contractile reserve that was markedly reduced in the hearts of males. Female hearts also exhibited reduction in the molecular markers of hypertrophy including mRNA levels of beta-myosin heavy chain ( $\beta$ MHC) and atrial natriuretic peptide (ANP) while expression of sarcoplasmic reticulum calcium ATPase 2A, reduced in males, was normalized in females.[30]

\section{Volume Overload Models}

Volume overload models lead to an increase in preload (end diastolic volume) that leads to the development of LV dilation and systolic dysfunction. Examples of volume overload models include valvular regurgitation (aortic or mitral insufficiency) or creation of an arterio-venous (AV) fistula to induce high cardiac output heart failure. Brower, Gardner, and Janicki 
developed an AV fistula model in rats in which a fistula is created between the aorta and inferior vena cava. Using this model, Brower, Gardner, and Janicki demonstrated that female rats developed less hypertrophy, less LV chamber dilatation while LV systolic function was preserved.[31] Similar to what was noted in pressure overload models, ovariectomy of females abolished these effects and estrogen replacement restored the female-gender associated patterns of remodeling in this model. [32]

\section{Transgenic and Knockout Mouse Models of Cardiomyopathy}

As shown in Table 2, multiple investigators have observed that female gender improves survival in transgenic or knockout mouse models of dilated cardiomyopathy and heart failure. Indeed, in many of these models in which mice develop LV dilatation, LV dysfunction and heart failure, female gender often protects mice heart failure progression, and death.[33-36] Moreover, gender specific effects in transgenic or knockout models may only be apparent after a stimulus to hypertrophy. For instance, we demonstrated in mice deficient in the angiotensin II type Ia receptor $\left(\mathrm{AT}_{1 \mathrm{a}} \mathrm{R}\right)$ that females developed less hypertrophy in the chronic phase postMI compared to male $\mathrm{AT}_{1 \mathrm{a}} \mathrm{R}$ KO mice.[37]

\section{Summary}

These data emphasize that in heart failure models, particularly those inducing pressure or volume overload, female gender is associated with reduced heart failure severity and mortality. These data also support the existence of gender-specific LV remodeling phenotypes in response to increased myocardial load. The mechanisms underlying the ability of the overloaded female heart to maintain normal contractile function are of increasing interest as elucidation of the signaling pathways or genes associated with these effects may unveil novel therapeutic targets. In many of these models, estrogen replacement promotes the favorable effects. As opposed to vascular disease models, however, these data are not consistent with the clinical literature. In response to pressure overload such as aortic stenosis or hypertension, women's hearts tend to develop a pattern of concentric hypertrophy while men's hearts dilate, exhibiting a pattern of eccentric hypertrophy.[5-8] However, in these studies, a majority of women were elderly and postmenopausal, and therefore had very low circulating levels of estrogen. Because the experimental models are often (though not invariably) performed in young adult animals, one possible hypothesis is that the estrogen mediated effect on the myocardial responses to overload may be age-dependent. Further work is of course needed to explore this possibility.

\section{Conclusions}

The gender specific responses observed in cardiovascular disease models underscore the importance of stratifying experimental data by gender to unveil possible gender-specific effects on the cardiovascular phenotype of interest. Perhaps more importantly, the observed gender differences in animal models supports that sex steroid hormone receptors regulate these cardiovascular responses. This family of transcription factors in addition to the signaling pathways and genes that they regulate, represent potentially exciting, novel therapeutic targets.

\section{Acknowledgments}

Dr. Patten is supported by NIH grant \#R01-HL078003.

\section{References}

1. American Heart Association. Heart Disease and Stroke Statistics: 2005 Statistical Supplement. Dallas, TX: American Heart Association; 2005. p. 1-60.

2. Lerner DJ, Kannel WB. Patterns of coronary heart disease morbidity and mortality in the sexes: a 26year follow-up of the Framingham population. Am Heart J 1986;111:383-390. [PubMed: 3946178] 
3. O'Meara E, Clayton T, McEntegart MB, McMurray JJV, Pina IL, Granger CB, Ostergren J, Michelson EL, Solomon SD, Pocock S, Yusuf S, Swedberg K, Pfeffer MA. Sex Differences in Clinical Characteristics and Prognosis in a Broad Spectrum of Patients With Heart Failure: Results of the Candesartan in Heart failure: Assessment of Reduction in Mortality and morbidity (CHARM) Program. Circulation 2007;115:3111-3120. [PubMed: 17562950]

4. Hayward CS, Kelly RP, Collins P. The roles of gender, the menopause and hormone replacement on cardiovascular function. Cardiovasc Res 2000;46:28-49. [PubMed: 10727651]

5. Carroll JD, Carroll EP, Feldman T, Ward DM, Lang RM, McGaughey D, Karp RB. Sex-associated differences in left ventricular function in aortic stenosis of the elderly. Circulation 1992;86:1099-1107. [PubMed: 1394918]

6. Douglas PS, Otto CM, Mickel MC, Labovitz A, Reid CL, Davis KB. Gender differences in left ventricle geometry and function in patients undergoing balloon dilatation of the aortic valve for isolated aortic stenosis. NHLBI Balloon Valvuloplasty Registry. Br Heart J 1995;73:548-554. [PubMed: 7626355]

7. Krumholz HM, Larson M, Levy D. Sex differences in cardiac adaptation to isolated systolic hypertension. Am J Cardiol 1993;72:310-313. [PubMed: 8342510]

8. Rohde LE, Zhi G, Aranki SF, Beckel NE, Lee RT, Reimold SC. Gender-associated differences in left ventricular geometry in patients with aortic valve disease and effect of distinct overload subsets. Am J Cardiol 1997;80:475-480. [PubMed: 9285661]

9. Wexler BC, Miller BF. Severe arteriosclerosis and other diseases in the rat produced by corticotrophin. Science 1958;127:590-591. [PubMed: 13529023]

10. Hamm TE Jr, Kaplan JR, Clarkson TB, Bullock BC. Effects of gender and social behavior on the development of coronary artery atherosclerosis in cynomolgus macaques. Atherosclerosis 1983;48:221-233. [PubMed: 6685520]

11. Adams MR, Kaplan JR, Clarkson TB, Koritnik DR. Ovariectomy, social status, and atherosclerosis in cynomolgus monkeys. Arteriosclerosis 1985;5:192-200. [PubMed: 3977777]

12. Hayashi T, Fukuto JM, Ignarro LJ, Chaudhuri G. Gender differences in atherosclerosis: possible role of nitric oxide. J Cardiovasc Pharmacol 1995;26:792-802. [PubMed: 8637195]

13. Hayashi T, Esaki T, Sumi D, Mukherjee T, Iguchi A, Chaudhuri G. Modulating role of estradiol on arginase II expression in hyperlipidemic rabbits as an atheroprotective mechanism. Proc Natl Acad Sci U S A 2006;103:10485-10490. [PubMed: 16801563]

14. Moroi M, Zhang L, Yasuda T, Virmani R, Gold HK, Fishman MC, Huang PL. Interaction of genetic deficiency of endothelial nitric oxide, gender, and pregnancy in vascular response to injury in mice. J Clin Invest 1998;101:1225-1232. [PubMed: 9502763]

15. Tolbert T, Thompson JA, Bouchard P, Oparil S. Estrogen-Induced Vasoprotection Is Independent of Inducible Nitric Oxide Synthase Expression: Evidence From the Mouse Carotid Artery Ligation Model. Circulation 2001;104:2740-2745. [PubMed: 11723029]

16. Akishita M, Ouchi Y, Miyoshi H, Kozaki K, Inoue S, Ishikawa M, Eto M, Toba K, Orimo H. Estrogen inhibits cuff-induced intimal thickening of rat femoral artery: effects on migration and proliferation of vascular smooth muscle cells. Atherosclerosis 1997;130:1-10. [PubMed: 9126642]

17. Chen S-J, Li H, Durand J, Oparil S, Chen Y-F. Estrogen Reduces Myointimal Proliferation After Balloon Injury of Rat Carotid Artery. Circulation 1996;93:577-584. [PubMed: 8565178]

18. Ailawadi G, Eliason JL, Roelofs KJ, Sinha I, Hannawa KK, Kaldjian EP, Lu G, Henke PK, Stanley JC, Weiss SJ, Thompson RW, Upchurch GR Jr. Gender Differences in Experimental Aortic Aneurysm Formation. Arteriosclerosis, Thrombosis \& Vascular Biology November 2004;24:21162122.

19. Sinha I, Cho BS, Roelofs KJ, Stanley JC, Henke PK, Upchurch GR. Female Gender Attenuates Cytokine and Chemokine Expression and Leukocyte Recruitment in Experimental Rodent Abdominal Aortic Aneurysms. Annals of the New York Academy of Sciences 2006;1085:367-379. [PubMed: 17182958]

20. Bakir S, Mori T, Durand J, Chen Y-F, Thompson JA, Oparil S. Estrogen-Induced Vasoprotection Is Estrogen Receptor Dependent : Evidence From the Balloon-Injured Rat Carotid Artery Model. Circulation 2000;101:2342-2344. [PubMed: 10821807]

21. Murphy E, Steenbergen C. Gender-based differences in mechanisms of protection in myocardial ischemia-reperfusion injury. Cardiovascular Research 2007;75:478-486. [PubMed: 17466956] 
22. Bae S, Zhang L. Gender Differences in Cardioprotection against Ischemia/Reperfusion Injury in Adult Rat Hearts: Focus on Akt and Protein Kinase C Signaling. J Pharmacol Exp Ther 2005;315:11251135. [PubMed: 16099927]

23. Brown DA, Lynch JM, Armstrong CJ, Caruso NM, Ehlers LB, Johnson MS, Moore RL. Susceptibility of the heart to ischaemia-reperfusion injury and exercise-induced cardioprotection are sex-dependent in the rat. J Physiol 2005;564:619-630. [PubMed: 15718263]Epub 2005 Feb 17

24. Wang M, Crisostomo P, Wairiuko GM, Meldrum DR. Estrogen receptor-alpha mediates acute myocardial protection in females. Am J Physiol Heart Circ Physiol 2006;290:H2204-H2209. [PubMed: 16415070]

25. Przyklenk K, Ovize M, Bauer B, Kloner RA. Gender does not influence acute myocardial infarction in adult dogs. Am Heart J 1995;129:1108-1113. [PubMed: 7754940]

26. Cavasin MA, Tao Z, Menon S, Yang X-P. Gender differences in cardiac function during early remodeling after acute myocardial infarction in mice. Life Sciences 2004;75:2181-2192. [PubMed: 15325844]

27. van Eickels M, Patten RD, Aronovitz MJ, Alsheikh-Ali A, Gostyla K, Celestin F, Grohe C, Mendelsohn ME, Karas RH. 17-Beta-Estradiol increases cardiac remodeling and mortality in mice with myocardial infarction. Journal of the American College of Cardiology 2003;41:2084-2092. [PubMed: 12798586]

28. Tamura T, Said S, Gerdes AM. Gender-related differences in myocyte remodeling in progression to heart failure. Hypertension 1999;33:676-680. [PubMed: 10024326]

29. Douglas PS, Katz SE, Weinberg EO, Chen MH, Bishop SP, Lorell BH. Hypertrophic remodeling: gender differences in the early response to left ventricular pressure overload. J Am Coll Cardiol 1998;32:1118-1125. [PubMed: 9768741]

30. Weinberg EO, Thienelt CD, Katz SE, Bartunek J, Tajima M, Rohrbach S, Douglas PS, Lorell BH. Gender differences in molecular remodeling in pressure overload hypertrophy. J Am Coll Cardiol 1999;34:264-273. [PubMed: 10400020]

31. Brower GL, Gardner JD, Janicki JS. Gender mediated cardiac protection from adverse ventricular remodeling is abolished by ovariectomy. Mol Cell Biochem 2003;251:89-95. [PubMed: 14575309]

32. Gardner JD, Brower GL, Janicki JS. Gender differences in cardiac remodeling secondary to chronic volume overload. J Card Fail 2002;8:101-107. [PubMed: 12016634]

33. Dash R, Schmidt AG, Pathak A, Gerst MJ, Biniakiewicz D, Kadambi VJ, Hoit BD, Abraham WT, Kranias EG. Differential regulation of p38 mitogen-activated protein kinase mediates genderdependent catecholamine-induced hypertrophy. Cardiovascular Research 2003;57:704-714. [PubMed: 12618232]

34. Kadokami T, McTiernan CF, Kubota T, Frye CS, Feldman AM. Sex-related survival differences in murine cardiomyopathy are associated with differences in TNF-receptor expression. J Clin Invest 2000;106:589-597. [PubMed: 10953034]

35. Gao X-M, Agrotis A, Autelitano DJ, Percy E, Woodcock EA, Jennings GL, Dart AM, Du X-J. Sex Hormones and Cardiomyopathic Phenotype Induced by Cardiac \{beta\}2-Adrenergic Receptor Overexpression. Endocrinology 2003;144:4097-4105. [PubMed: 12933684]

36. Xiong S, Van Pelt CS, Elizondo-Fraire AC, Fernandez-Garcia B, Lozano G. Loss of Mdm4 Results in p53-Dependent Dilated Cardiomyopathy. Circulation 2007;115:2925-2930. [PubMed: 17533180]

37. Bridgman P, Aronovitz MA, Kakkar R, Oliverio MI, Coffman TM, Rand WM, Konstam MA, Mendelsohn ME, Patten RD. Gender-specific patterns of left ventricular and myocyte remodeling following myocardial infarction in mice deficient in the angiotensin II type 1a receptor. Am J Physiol Heart Circ Physiol 2005;289:H586-H592. [PubMed: 15764682]

38. Holm P, Andersen HL, Arroe G, Stender S. Gender Gap in Aortic Cholesterol Accumulation in Cholesterol-Clamped Rabbits : Role of the Endothelium and Mononuclear-Endothelial Cell Interaction. Circulation 1998;98:2731-2737. [PubMed: 9851960]

39. Johnson MS, Moore RL, Brown DA. Sex differences in myocardial infarct size are abolished by sarcolemmal KATP channel blockade in rat. Am J Physiol Heart Circ Physiol 2006;290:H2644 H2647. [PubMed: 16473955] 
40. Forman DE, Cittadini A, Azhar G, Douglas PS, Wei JY. Cardiac morphology and function in senescent rats: gender-related differences. J Am Coll Cardiol 1997;30:1872-1877. [PubMed: 9385921]

41. Skavdahl M, Steenbergen C, Clark J, Myers P, Demianenko T, Mao L, Rockman HA, Korach KS, Murphy E. Estrogen receptor-\{beta\} mediates male-female differences in the development of pressure overload hypertrophy. Am J Physiol Heart Circ Physiol 2005;288:H469-H476. [PubMed: 15374829]

42. Olsson MC, Palmer BM, Leinwand LA, Moore RL. Gender and aging in a transgenic mouse model of hypertrophic cardiomyopathy. Am J Physiol Heart Circ Physiol 2001;280:H1136-H1144.

[PubMed: 11179057] 


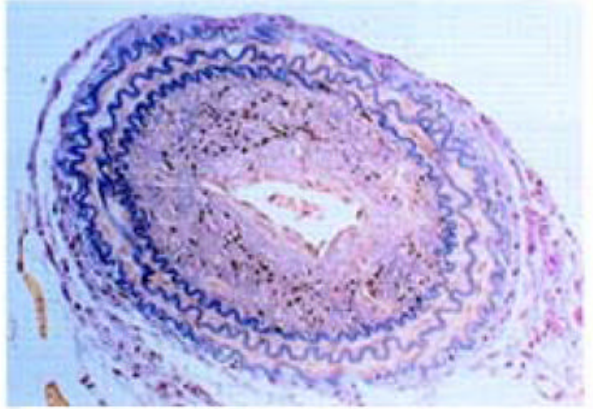

Male-Intact

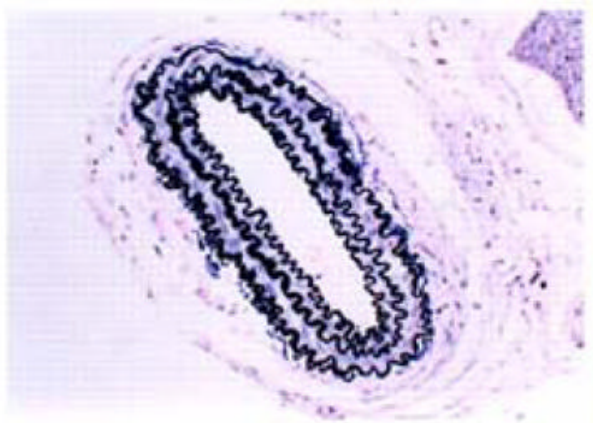

Female-Intact

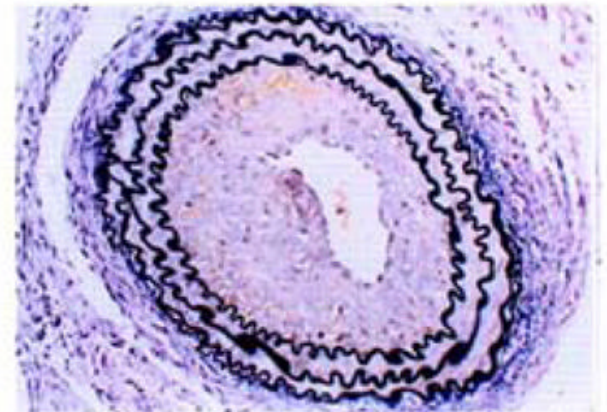

Female-Ovex

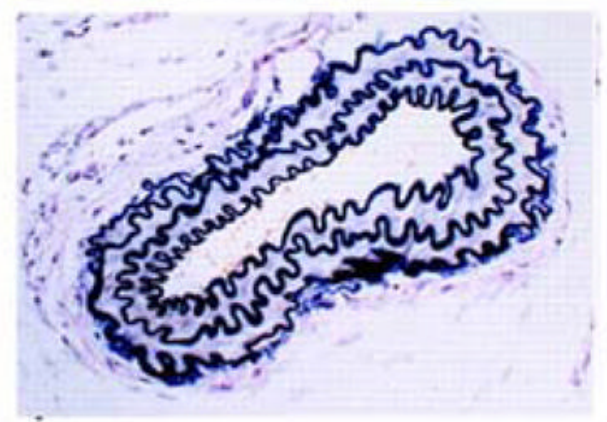

Female-Ovex + E2

Figure 1.

Light micrographs of injured carotid arteries from male and female wild type mice 28 days after ligation injury. Mice were studied either intact or after ovariectomy (ovex). Female mice were treated with $17 \beta$-estradiol (E2) or vehicle. These figures demonstrate a marked reduction in the vascular injury response in females that is lost upon ovariectomy and restored by estrogen replacement. Reproduced with permission from [15]. 


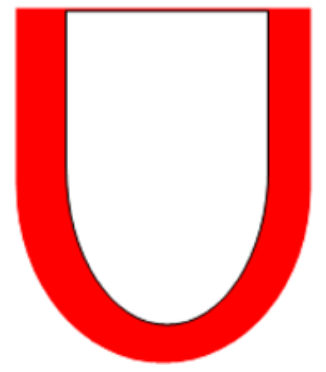

Normal

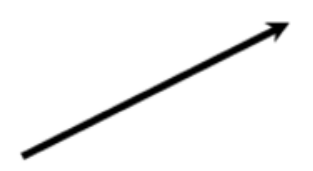

Hypertrophic

Stimulus

(Pressure or Volume

Overioad)

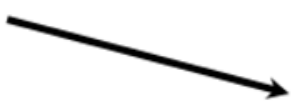

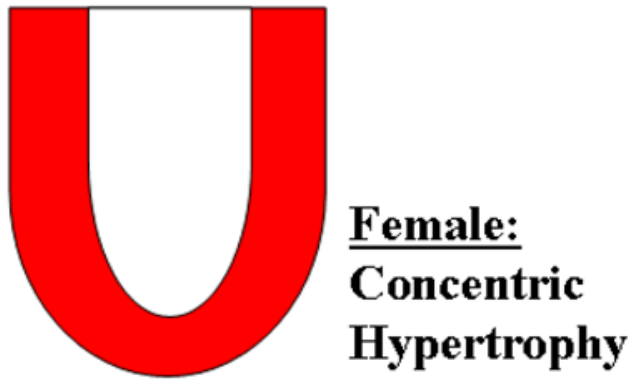

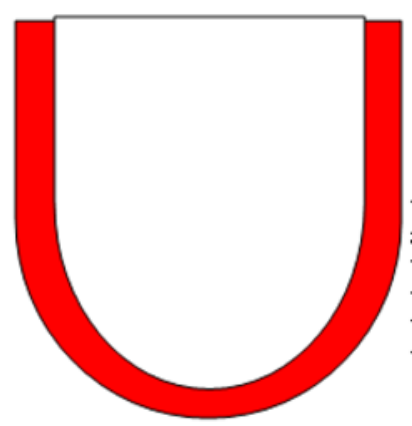

Male: Eccentric Hypertrophy

Figure 2.

Schematic of gender-specific patterns of LV remodeling in response to a hypertrophic stimulus such as pressure or volume overload. Typically, females develop a concentric pattern of hypertrophy characterized by an increase in wall thickness and maintenance of normal chamber size. Male hearts, however, tend to develop more of an eccentric pattern of hypertrophy in which the LV chamber dilates but wall thickness remains the same. 
Table 1

Gender Differences in Models of Atherosclerosis and Vascular Injury

\begin{tabular}{llccc}
\hline Model & Method & Species & Reference(s) & Effects in Females \\
\hline Atherosclerosis & High Cholesterol Diet & Macaques & {$[10,11]$} & Reduced Atherosclerosis \\
& High Cholesterol Diet & Rabbit & {$[12,13,38]$} & Reduced Atherosclerosis \\
Vascular Injury & Cuff Induced injury & Mouse & {$[14]$} & Reduced intimal and medial thickness \\
& Cuff Induced Injury & Rat & {$[16]$} & Reduced intimal and medial thickness \\
& Balloon Injury & Rat & {$[17]$} & Reduced intimal and medial thickness \\
Abdominal Aortic & Carotid Artery Ligation & Mouse & {$[15]$} & Reduced intimal and medial thickness \\
Aneurysm & Elastase Perfusion of Infra- & Rat & {$[18,19]$} & Reduced incidence and severity of \\
Formation & renal Aorta & & aneurysm formation \\
& & & \\
\end{tabular}


Table 2

Gender Differences in Models of Heart Failure and LV Remodeling

\begin{tabular}{|c|c|c|c|c|}
\hline Model & Method & Species & Reference(s) & Effects in Females \\
\hline \multirow[t]{2}{*}{ Myocardial Injury } & Permanent Coronary Ligation & Mouse & [37] & $\begin{array}{l}\text { Female AT1aR KO mice } \\
\text { demonstrated reduced LV } \\
\text { remodeling compared to } \\
\text { males while no difference was } \\
\text { seen in wild types. }\end{array}$ \\
\hline & Ischemia Reperfusion & Rat & {$[22,39]$} & $\begin{array}{l}\text { Diminished infarct size after } \\
2 \mathrm{hr} \text { ischemia and reperfusion. } \\
\text { This was associated with } \\
\text { greater activation of Akt in the } \\
\text { ischemic zone }\end{array}$ \\
\hline \multirow[t]{4}{*}{ Pressure Overload } & Spontaneous Hypertension & Rat & {$[28]$} & $\begin{array}{l}\text { Delay in the onset of heart } \\
\text { failure and preservation of } \mathrm{LV} \\
\text { systolic function }\end{array}$ \\
\hline & Ascending Aortic Banding & Rat & {$[30]$} & $\begin{array}{l}\text { Preservation of normal LV } \\
\text { function, reduced expression } \\
\text { of ANP and beta-MHC. }\end{array}$ \\
\hline & Senescent Rats & Rat & {$[40]$} & $\begin{array}{l}\text { Preservation of normal LV } \\
\text { function, concentric } \\
\text { remodeling, less fibrosis and } \\
\text { mitral regurgitation }\end{array}$ \\
\hline & Tranverse Aortic Constriction (TAC) & Mouse & [41] & $\begin{array}{l}\text { Reduced pressure overload } \\
\text { induced hypertrophy. }\end{array}$ \\
\hline Volume Overload & AV Fistula Induced Volume Overload & Rat & {$[31,32]$} & $\begin{array}{l}\text { Reduced heart failure; } \\
\text { preservation of normal LV } \\
\text { chamber size and function. }\end{array}$ \\
\hline Hypertrophic CMP & $\alpha$-MHC mutation & Mouse & {$[42]$} & $\begin{array}{l}\text { Concentric remodeling at } 1 \\
\text { year at which time males } \\
\text { exhibited LV dilation/ } \\
\text { eccentric remodeling. }\end{array}$ \\
\hline \multirow[t]{4}{*}{ Dilated Cardiomyopathy } & Phospholamban over-expression & Mouse & {$[33]$} & $\begin{array}{l}\text { Protection from mortality and } \\
\text { heart failure despite similar } \\
\text { degrees of contractile } \\
\text { dysfunction and LVH } \\
\text { compared to males. }\end{array}$ \\
\hline & TNF $\alpha$ Over-expression & Mouse & [34] & $\begin{array}{l}\text { Improved survival, less } \\
\text { apoptosis, and less LV } \\
\text { dilatation and dysfunction } \\
\text { compared to males. }\end{array}$ \\
\hline & Conditional $\mathrm{KO}$ of MDM 2 & Mouse & [36] & $\begin{array}{l}\text { Better survival, less LV } \\
\text { dysfunction and apoptosis } \\
\text { compared to males. }\end{array}$ \\
\hline & $\beta 2$-adrenergic receptor Over-expression & Mouse & [35] & $\begin{array}{l}\text { Reduced heart failure; } \\
\text { preservation of normal LV } \\
\text { chamber size and function. }\end{array}$ \\
\hline
\end{tabular}

